\title{
An Investigation of PEFC Sub-Zero Startup: Influence of Initial Conditions and Residual Water
}

Revised 21/02/18

\author{
P. Stahl ${ }^{1 *}$, J. Biesdorf ${ }^{2}$, P. Boillat ${ }^{2,3}$, K. A. Friedrich ${ }^{4}$ \\ ${ }^{1}$ ElringKlinger AG, 72581 Dettingen/Erms, Germany \\ ${ }^{2}$ Electrochemistry Laboratory (ECL), Paul Scherrer Institut (PSI), 5232 Villigen PSI, Switzerland \\ ${ }^{3}$ Neutron Imaging and Activation Group (NIAG), Paul Scherrer Institut (PSI), 5232 Villigen PSI, \\ Switzerland \\ ${ }^{4}$ Institute of Engineering Thermodynamics, German Aerospace Center (DLR), 70569 Stuttgart, \\ Germany
}

[*] Corresponding author: peter.stahl@elringklinger.com

\begin{abstract}
Isothermal cold starts of polymer electrolyte fuel cells were performed at sub-zero temperatures and analyzed by the means of neutron radiography in order to unravel the relation between the preconditioning of the cell and the cold start capability. It was found out that the initial humidification state of the membrane (determined by its resistance) has a clear correlation with the duration of the initial phase of the cold start, but not with the total duration of startup until cell failure. In the experimental setup the impact of realistic and commercial sealing solutions was taken into account by adding an edge channel. The impact of water accumulations in this region on the cold start capability was assessed. Liquid water located in the outer perimeter of a cell could be directly verified to freeze during cell cool down by a novel dual spectrum neutron radiography method. The amount of water accumulated in the outer cell perimeter showed some correlation with the total duration of the cold start. It was found out that residual water located in the edge channel can initiate freezing of a substantial part of the active area nearby.
\end{abstract}

Keywords: Polymer Electrolyte Fuel Cell, Water Management, Residual Water, Cold Start, Neutron Radiography, Dual Spectrum, Imaging Techniques, Sealing Concepts 


\section{Introduction}

Much attention was paid to cold starts of polymer electrolyte fuel cells (PEFCs) in the last few years as they will be mainly used in mobile vehicles such as cars, forklifts or delivery vans where cold start capability is essential. As has been reported in literature, residual water can be present in a cell prior to a cold start originating from previous cell operation. Residual water may be located in the membrane, catalyst layer (CL), micro porous layer (MPL), gas diffusion layer (GDL) and in the flowfield. Its amount and distribution strongly depends on the applied shutdown procedure, such as cell cooling profile and purging of the gas compartments after cell operation. In a previous work, we showed that in certain cell designs, water can remain in the outer perimeter of the flowfield, if this region is not accessible for a direct gas feed [1]. Even after purging with dry gas for up to an hour, liquid water droplets can remain inside the cell.

After a cell shutdown, temperature can fall below $0{ }^{\circ} \mathrm{C}$ under the influence of environmental conditions. As system downtime can easily exceed several hours, residual water is most likely to be frozen at an upcoming cold start, accelerating the freezing of additional product water. Several studies proved the existence of supercooled water inside fuel cells far below $0{ }^{\circ} \mathrm{C}$ [2-5]. Its transition to ice requires a sufficient activation energy, whereby the activation barrier is lowered with lower temperatures or the presence of nuclei [6]. Frozen residual water can act as a freezing nucleus for product water generated during a cold start and hence can have a negative impact on cold start capability. Once freezing is initiated locally, it will propagate along the entire water cluster. As shown by X-ray tomography measurements by Eller et al. [7], water clusters exceed over a significant fraction of the cell area and ice formation can spread out.

There is still an ongoing debate about the influence of water located in the membrane on cold start capability. Membrane water can be generally distinguished into freezable and non-freezable water. To measure the membrane water content, the relation between the number of water molecules and $\mathrm{SO}_{3}{ }^{-}$end groups, denoted by $\lambda$, is introduced. Strong binding forces of water molecules to the sulfonic acid end groups of the membrane $\left(\mathrm{SO}_{3}{ }^{-}\right)$prevent a limited fraction from freezing. Up to $\lambda=14$ of non-freezable water was reported [8], which maintains ionic conductivity even at temperatures far below $0^{\circ} \mathrm{C}$. Thompson et al. proposed that the remaining free water can be frozen [9]. These results were contradicted by another group reporting that ice formation in the membrane 
could only be observed at very high swelling states such as $\lambda=50$ [10]. During a cold start, water uptake by the membrane is desirable as it preserves a part of residual or product water from freezing. Therefore the membrane's initial humidification state is crucial for the operation time as a dry membrane can absorb a higher amount of product water [11-13]. However, Chacko et al. did additionally show, that an excessively dry membrane inhibits a successful cold start as its poor ionic conductivity does not allow for drawing any current from the cell [14].

Removal of liquid water prior to a cold start could be crucial for a successful cold start. Especially in technical cells, geometrical restrictions can promote water accumulations. So far little attention was paid to the influence of residual water on cold start capability, and this work aims to close this gap. In this work the freezing of residual water droplets in the flowfield during the cooling of a cell was measured with a direct method in a cell of technically relevant size. A recently developed dual spectrum neutron radiography method was used thereby. Moreover the impact of residual water in the flowfield as well as water located in the membrane on cold start capability is shown, whereby water distribution is imaged by neutron radiography. In the last part of this work, we present neutron radiography images, proving that preferential water percolation pathways in GDLs exist.

\section{Experimental}

\subsection{Cell setup}

Experiments were performed with a $50 \mathrm{~cm}^{2}$ single cell with graphitic bipolar plates, described in [1] in detail. A catalyst coated membrane (CCM) comprising a reinforced perfluorosulfonic acid (PFSA) membrane with a thickness of $15 \mu \mathrm{m}$ was employed with a $200 \mu \mathrm{m}$ thick GDL (porosity $70 \%$, PTFE content $4 \%$ ) including a MPL. For the cold start basically the same setup as described in [15] was used. The cell was liquid cooled with a hydrogen-free fluid (Fluorinert FC-770, 3M) in order to reduce neutron attenuation by the coolant in the field of view. Additionally heating pads were employed on the outer cell surface in order to enable a precise temperature control. Dry nitrogen was blown on the outer cell surface to avoid water condensation in the neutron radiography field of view. The ohmic cell resistance (high frequency resistance, HFR) was measured at 5kHz.

\subsection{Experimental protocol}


Cells were operated in an automated protocol comprising 9 steps as shown in Table $1 . \mathrm{V}_{\text {an }}$ and $\mathrm{V}_{\text {ca }}$ are the gas volume flows and $\lambda_{\mathrm{an}}$ and $\lambda_{\mathrm{ca}}$ the stoichiometries on the anode and cathode side, respectively and $\mathrm{T}_{\text {cell }}$ denotes the cell temperature. The cells were operated with high stoichiometries of 8.5 as the cell area is small compared to usual commercial cells, in order to obtain relevant gas velocities in the flowfield channels in terms of water transport. The gas inlet pressure on anode and cathode side was set to 1.3 and 1.2 bar $_{\mathrm{a}}$, respectively. Compared to our previous work, instead of conditioning the cell by humidified gases, current was drawn in order to produce liquid water in the cell, remaining as residual water prior to the cold startup [15]. The cell was then cooled to $-15^{\circ} \mathrm{C}$ in order to assure entire freezing of the liquid water in the cell before being heated to the desired startup temperature. When the open circuit voltage is reached after charging the anode with hydrogen and the cathode with air, current is drawn from the cell until the cell voltage $\mathrm{U}_{\text {cell }}$ falls below $0.2 \mathrm{~V}$.

\subsection{Neutron imaging}

Neutron radiography was performed during the whole cold start in order to analyze the in-plane water distribution in the cell. Experiments were carried out at the Swiss Spallation Neutron Source (SINQ), at the ICON Beamline [16], whereas through-plane imaging was performed in order to analyze the in-plane water distribution. The law of Lambert Beer describes the relation between beam intensity coming from the neutron source $\mathrm{I}_{0}$ and the remaining beam intensity $\mathrm{I}$ being analyzed by the detector in form of the optical density $\Delta[17]$

$$
\Delta=-\ln \left(\frac{I}{I_{0}}\right)=\delta N \sigma=\delta \Sigma
$$

The properties of the imaged sample are represented by its thickness $\delta$, molar density $\mathrm{N}$ and microscopic neutron cross section $\sigma$. $\Sigma$ denotes the macroscopic cross section or attenuation coefficient. The remaining neutron flux behind the sample is analyzed with a scintillator and a camera system (Andor iKon-L, 2048x2048 pixels $^{2}$ ). The reached effective resolution was $440 \mu \mathrm{m}$ (full width at half maximum, FWHM). In order to extract the local water thickness in the cell $\delta_{\mathrm{H} 2 \mathrm{O}}$ a reference image of the cell, with the intensity $\mathrm{I}_{\text {ref, }}$, is taken after drying the cell with pure nitrogen. The water thickness can be calculated with the macroscopic cross section of water $\Sigma_{\mathrm{H} 2 \mathrm{O}}=0.45 \mathrm{~mm}^{-}$ 1 


$$
\delta_{H 2 O}=\frac{\ln \left(\frac{I}{I_{\text {ref }}}\right)}{-\Sigma_{H 2 O}} .
$$

Residual water or electrochemically produced water in a PEFC during a cold start is susceptible to freeze. Neutron radiography, performed with a static energy spectrum is not able to distinguish between water and ice. This restriction was resolved by Biesdorf et al. [5] by introducing a dual spectrum method. Thereby neutron radiographs are taken alternately with two different neutron energy spectra. One with a beryllium filter introduced into the beam and one without a filter. The relation between optical densities of water and ice changes with the neutron energy $[18,19]$ and can be used to detect phase transitions. $\sigma_{\text {rel }}$ is calculated with the optical densities $\Delta_{\text {filter }}$ and $\Delta_{\text {nofilter }}$ and cross sections $\sigma_{\text {filter }}$ and $\sigma_{\text {nofilter }}$ with and without filter, respectively

$$
\sigma_{\text {rel }}=\frac{\Delta_{\text {filter }}}{\Delta_{\text {nofilter }}}=\frac{\sigma_{\text {filter }} N \delta}{\sigma_{\text {nofilter }} N \delta}=\frac{\sigma_{\text {filter }}}{\sigma_{\text {nofilter }}} .
$$

The contrast of $\sigma_{\text {rel }}$ between ice and water amounts to about $1.6 \%$, as found out by Biesdorf et al. and confirmed in our previous work [5,15]. Unfiltered images are taken with a mean energy of 8.53 $\mathrm{meV}$ [16], the filter reduces the mean energy to $5.24 \mathrm{meV}$ [5]. Here the method will only be applied under static operation conditions in order to avoid interferences by changing local water thicknesses and to obtain stable values for $\sigma_{\text {rel }}$. The imaging setup is a tradeoff between spatial and temporal resolution. Various approaches in order to shift the limits of dual spectrum were discussed in the literature [20]. In order to estimate repeatability and error of the measurements it is referred to other publications, where neutron radiography and the dual spectrum method were studied extensively $[20,21]$.

\subsection{Image processing}

In order to mitigate the impact of reduced intensity of the filtered beam, images were taken over $9 \mathrm{~s}$ while the neutron beam was filtered and over $3 \mathrm{~s}$ without a filter in the beam. Each, filtered and unfiltered images are processed separately with a median filter, intensity correction of the neutron beam and a flat-field correction. The images were merged over a measurement period of $1 \mathrm{~min}$. The unfiltered image gives the local water thickness with Eq. (2). Neutron radiography images are 
analyzed as depicted in Figure 1, divided into 8 different areas, whereby water thickness is averaged in each area separately. The inlet and outlet areas of the anode and cathode flowfield are excluded from the analysis as accumulated water on the outer surface led to unstable values for the water thickness there.

\subsection{Cold start analysis}

For better comparison of cold starts with different current densities, the accumulated charge current density $\mathrm{q}$ is introduced as the integrated current density $\mathrm{i}$ over time $\mathrm{t}$

$$
q=\int_{t} i d t
$$

Figure 2 shows an exemplary cold start at $-5{ }^{\circ} \mathrm{C}$ consisting out of the different phases I-III (membrane water uptake, stable cell operation, cell breakdown). The assignment of the accumulated charge current densities $\mathrm{q}_{\text {uptake }}, \mathrm{q}_{\text {stable, }}, \mathrm{q}_{\text {failure }}, \mathrm{q}_{\text {acc }}$ and $\mathrm{q}_{\mathrm{CS}}$ to the different phases is indicated. The initial decrease of the HFR and the increase of the cell voltage can be attributed to membrane humidification. During the stable phase (II), electrochemically produced water drains into CL, GDL and flowfield. As soon as water begins to freeze and likely leads to membrane dryout by preventing water from back-diffusion into the membrane [22] or by a change in water saturation pressure, the HFR immediately increases and the cell voltage decreases during phase III until cell failure. The first local minimum of the HFR is assumed as the boundary between phase I and II. The beginning of phase III is defined by a voltage decrease of more than $20 \mathrm{mV}$ compared to the average of phase II. In some cases no stable cell operation is reached and no phase II can be identified.

\section{Results and Discussion}

\subsection{Influence of the Initial HFR on Cold Start Capability}

We performed 42 cold starts at $-5^{\circ} \mathrm{C}$ and current densities between 0.02 and $0.2 \mathrm{~A} \mathrm{~cm}^{-2}$. Cells were started up with residual water in certain cell areas, as well as without any visible water in the flowfield. The HFR at $25{ }^{\circ} \mathrm{C}$ before the cold starts varied between 0.069 and $0.199 \Omega \mathrm{cm}^{2}$ as Figure 3 indicates. The differences arise from the variation of the conditioning procedure. Particularly for 
some cold starts residual water was forced to remain in the cell and caused low HFR values. qCS (the charge drawn during the entire cold start) ranges from 6.6 to $72.9 \mathrm{C} \mathrm{cm}^{-2}$ without any obvious correlation to the HFR. The mean value of the HFR is $0.13 \Omega \mathrm{cm}^{2}$ with a standard deviation of $0.027 \Omega \mathrm{cm}^{2}$ while $\mathrm{q}_{\mathrm{CS}}$ has a mean value of $29.3 \mathrm{C} \mathrm{cm}^{-2}$ and a standard deviation of $12.2 \mathrm{C} \mathrm{cm}^{-2}$. Two outliers reached more than twice the mean value with 68 and $72.9 \mathrm{C} \mathrm{cm}^{-2}$.

In the first phase (phase I in Figure 2) of a cold start product water can be drained into the CL or it can be absorbed by the membrane. The latter results in a decreasing HFR and hence an increasing cell voltage [14]. As water uptake capacity of the membrane is limited and particularly lower at low temperatures [13], water absorption by the membrane ceases from a certain point and water transport is shifted towards the CL.

The length of phase I should increase with the HFR and converge to a maximum value. Figure 3 shows the accumulated charge current density between start of operation and the point when a minimum HFR is reached for the first time quptake. Assuming that in the initial phase no water is transported to the CL or GDL (as done in Ref. [14]), the value corresponds to the amount of water absorbed by the membrane. quptake remains stable and low for HFR values below $0.12 \Omega \mathrm{cm}^{2}$, indicating that the membrane is fully humidified before the cold starts in these cases. Above $0.12 \Omega$ $\mathrm{cm}^{2}$, a clear trend is seen that $\mathrm{q}_{\text {uptake }}$ rises with the HFR, indicating that the membrane is capable for water uptake. This coincides well with the literature [23].

Previous publications mainly related their argumentation to the duration of a cold start or the produced water mass during a whole cold start. Both parameters are comparable to q $\mathrm{CS}$ in our work. Chacko et al. did not find a direct influence of the initial HFR on the produced water mass as long as the HFR is below $0.5 \Omega \mathrm{cm}^{2}$ [14]. Also Oberholzer et al. did not find a strong correlation between HFR and the entire operating time while humidification during conditioning was varied from 10 to $80 \%$ r.H. [24]. Both works conducted isothermal cold starts at $-10{ }^{\circ} \mathrm{C}$. At lower temperatures as $-30{ }^{\circ} \mathrm{C}$ Tajiri et al. discovered, that membrane humidification and the subsequent freezing in the CL seem to be overlaid, as the cell voltage already decreased significantly before the HFR could even reach its minimum [25]. 
Our results at $-5{ }^{\circ} \mathrm{C}$ are in line with these findings. $\mathrm{q}_{\mathrm{CS}}$ did not show any correlation to the initial HFR, which was varied between 0.069 and $0.199 \Omega \mathrm{cm}^{2}$ (Figure 3). Other effects than the initial membrane humidification seem to dominate the overall cold start capability at these temperatures.

\subsection{Influence of Residual Water on Cold Start Capability}

Viable sealing solutions for mass production of PEFCs require an adapted cell design, particularly in the outer perimeter of the active area. Especially sealing solutions based on a reinforcing frame (sub-gasket) at the outer perimeter of the CCM require large free volumes between the gasket and flowfield. In a previous work we have shown that if these free volumes are exposed to a direct gas flow, they can act as a bypass around the flowfield, lowering the stoichiometry in the active area [1]. Otherwise, if they are isolated from a direct gas feed, they are susceptible to flooding. In the latter case residual water can remain in the cell even after prolonged purging with dry gas as time constants for water transport can be shifted to hours in the isolated areas. Two different negative influences of residual water on cold start capability are conceivable:

- Residual water freezes in the cell and can pose a nucleus for frost initiation of electrochemically produced water during cold starts. Hence cold start capability can be reduced as the formation of supercooled water is impeded.

- Residual water clusters, e.g. in the outer perimeter of the cell, can be redistributed during cell downtime by in-plane diffusion over the membrane plane and thus lower the membrane water uptake capacity for cold starts.

The latter case was not described in literature relating to cold starts so far. But indirectly it can be concluded that humidification of the membrane by in-plane diffusion has a negative influence on cold start capability as water uptake capacity of the membrane is lowered and product water transport is shifted towards the CL and GDL pores where it is susceptible to freezing [6,12,26]. It has to be considered that in-plane diffusion in the membrane is a very slow process. Equilibration can take days or weeks, as indicated by a falling HFR after shutting down a cell after operation.

We investigated the influence of residual water clusters on cold start capability with an adapted cell setup. Between sealing structure and flowfield a gap (edge channel) of $1 \mathrm{~mm}$ width is left which leads to an accumulation of water as shown in our previous work [1]. An edge land continuously surrounds the flowfield which impedes convective flow in the edge channel. Water can only be 
exchanged between flowfield and edge channel by lateral permeation through the GDL. Product water was generated by operating the cell under load before a cold start was performed.

Before the cold start the major part of water remains in the bottom part of the edge channel (bottom part of region $\mathrm{G}$ in Figure 1), which is possibly an effect of gravitation and of a humidity gradient from in- to outlet during conditioning. The outlet regions are filled up with water, they act as a water trap and can almost not been dried out. In some cases, water droplets were also located on the left and right hand sided edge channel, but they vanished after a few cold starts. The top part of the edge channel was permanently free of droplets.

Figure 4 shows the relative attenuation $\sigma_{\text {rel }}$ of a water cluster located in the bottom part of region $G$ during cooling down of the cell from 25 to $-15{ }^{\circ} \mathrm{C}$. The cluster has an area of around $35 \mathrm{~mm}^{2}$ and a mean water thickness of $0.63 \mathrm{~mm}$. Neither current was drawn nor the cell was fed with gases during cool down.

A negative step of the relative attenuation $\sigma_{\text {rel }}$ is seen at a cell temperature between 0 and $-10{ }^{\circ} \mathrm{C}$ as it is characteristic for a phase transition from liquid water to ice. The step amounts to about $2 \%$. In the flowfield, no phase transitions could be observed. The mean water thickness there was small compared to that in the edge channel which resulted in $\sigma_{\text {rel }}$ being impacted by a large noise. The results coincide well with the results from Biesdorf et al., where a contrast for $\sigma_{\text {rel }}$ of $1.6 \%$ was found for a phase transition from water to ice [5]. So it is verified unambiguously that residual water clusters in PEFCs immediately freeze when cooling down the cell to $<0{ }^{\circ} \mathrm{C}$.

In the following we will emphasize phase II and III of a cold start since all processes beside membrane water uptake are expected to have a strong influence here. The residual water in the cell - apart from water located in the membrane - is expected to mainly affect phase II and III of a cold start. For that reason we exclude the membrane humidification phase I from the subsequent considerations and refer to the accumulated charge density of phase II and III $\mathrm{q}_{\text {acc }}$ in the following.

16 subsequent cold starts were performed, where the water content in the cell and particularly in the edge channel varied. Figure 5 shows the initial water thickness for each of the cold starts in both, the edge channel region $\left(\delta_{\mathrm{H} 2 \mathrm{O}, \mathrm{EC}}\right)$ and the flowfield $\left(\delta_{\mathrm{H} 2 \mathrm{O}, \mathrm{FF}}\right)$ over $\mathrm{q}_{\mathrm{acc}}$ as well as the $\mathrm{HFR}$ at $25{ }^{\circ} \mathrm{C}$ before cooling down the cell. 
$\delta_{\mathrm{H} 2 \mathrm{O}, \mathrm{EC}}$ and $\delta_{\mathrm{H} 2 \mathrm{O}, \mathrm{FF}}$ were averaged over region $\mathrm{G}\left(1.4 \mathrm{~cm}^{2}\right)$ and regions A-E $\left(34 \mathrm{~cm}^{2}\right)$, respectively. Negative values for the water thickness are obtained in some cases. A conceivable reason is that residual water or water on the outer cell surface in the reference image falsifies the neutron radiograms as the images for all cold starts are referenced to one global reference image for which the cell was dried extensively. Also beam hardening or softening effects can lead to the present errors [20].

For the temporal evolution of phase II and III, no influence of the initial HFR is expected as a full membrane humidification is supposed. The assumption is confirmed by the absence of any correlation between $\mathrm{q}_{\mathrm{acc}}$ and the HFR and a strong variation of the initial HFR in the range for $\mathrm{q}_{\text {acc }}$ between 20 and $25 \mathrm{C} \mathrm{cm}^{-2}$ (top part of Figure 5).

All cold starts reached values for $\mathrm{q}_{\mathrm{acc}}$ between 6.6 and $28.7 \mathrm{C} \mathrm{cm}^{-2}$. The strong variation can be explained with the theory of supercooled water, as in the absence of any frost initiation, the water in the cell can remain liquid [2-5]. Once a nucleus locally initiates freezing, the frost can propagate throughout the cell and lead to a cell failure [15,27]. This theory is confirmed by two cold starts with very high values for $\mathrm{q}_{\mathrm{CS}}\left(68\right.$ and $72.9 \mathrm{C} \mathrm{cm}^{-2}$, see Figure 3$)$, where supercooled water persisted in the cells for more than 10 min. These cold starts were not observed by neutron imaging.

Thereby the water thickness in the edge channel $\delta_{\mathrm{H} 2 \mathrm{O}, \mathrm{EC}}$ shows a very slight correlation to qacc. Even cold starts with more than $0.3 \mathrm{~mm}$ of water in the edge channel reached values of 16.5 to $23.5 \mathrm{C} \mathrm{cm}^{-}$ ${ }^{2}$ for $\mathrm{q}_{\text {acc. }}$ But the cold start with the lowest value for $\mathrm{q}_{\text {acc }}$ also exhibited the highest flowfield water thickness with more than $0.4 \mathrm{~mm}$, indicating a negative influence of the residual water. Also the three cold starts with highest values for $\mathrm{q}_{\text {acc }}$ have relatively low initial water thicknesses in both, edge channel and flowfield.

The water thickness in the flowfield $\delta_{\mathrm{H} 2 \mathrm{O}, \mathrm{FF}}$ shows a slight correlation to $\mathrm{q}_{\mathrm{acc}}$, lower values of $\mathrm{q}_{\text {acc }}$ correlate with higher initial water thicknesses and vice versa. Regarding the minor influence of $\delta_{\mathrm{H} 2 \mathrm{O}, \mathrm{EC}}$ on the cold start capability it should be taken into account that the absolute water mass in the edge channel is significantly lower than in the flowfield, although the water thicknesses do not indicate this difference. 
The water content in edge channel and flowfield could hardly been varied independently, hence a separate investigation of the influence of residual water in both regions was not possible. However we found out that residual water generally has a slight negative influence on $\mathrm{q}_{\text {acc }}$. But the present data is not sufficiently supported by statistics to quantify a correlation.

We pick out one of the cold starts with $\mathrm{q}_{\mathrm{CS}}=25.3 \mathrm{C} \mathrm{cm}^{-2}$ (marked with an arrow in Figure 5), with initial values for the water thickness of $\delta_{\mathrm{H} 2 \mathrm{O}, \mathrm{EC}}=0.11 \mathrm{~mm}$ and $\delta_{\mathrm{H} 2 \mathrm{O}, \mathrm{FF}}=0 \mathrm{~mm}$. A long operation time was reached in spite of residual water in the edge channel. The major part of residual water was located in the bottom part of the edge channel. The mean water thickness before the cold start in the right, left and top side of the edge channel amounts to only $0.06 \mathrm{~mm}$ compared to $0.31 \mathrm{~mm}$ in the bottom part. Figure 6 shows the evolution of the cell voltage and HFR over the operation time. Also the increase of water thickness relative to the beginning of the cold start $\Delta \delta_{\mathrm{H} 2 \mathrm{O}}$ is shown. Both, cell voltage and HFR exhibit a sharp bend at $3.1 \mathrm{~min}$ or $7.3 \mathrm{C} \mathrm{cm}^{-2}$ after startup. Subsequently HFR rises up from 0.2 to $0.5 \Omega \mathrm{cm}^{-2}$ and the cell voltage falls down from 0.8 to $0.2 \mathrm{~V}$. The water layer grows up almost equally distributed over the cell plane in regions $\mathrm{A}-\mathrm{C}$, without respect to the different initial water thicknesses. Water thickness for region $\mathrm{D}$ is not shown here as condensing water on the cell surface interferes with the results there. Region E exhibits a slightly reduced water accumulation rate. By scanning the whole flowfield, it was found that in the most bottom part of region E, here denoted as region I (cf. Figure 1), with an area of $2.4 \mathrm{~cm}^{2}$, less than half the water mass was accumulated compared to the cell average. In contrast to the bottom part, the top part of the edge channel accommodates almost no residual water, the mean initial water thickness amounts to only $0.02 \mathrm{~mm}$ there. In the adjacent segment in the flowfield, region $\mathrm{H}$ (cf. Figure 1) with an area of $2.4 \mathrm{~cm}^{2}$, no differing water accumulation rate can be found compared to the average value.

A detailed observation of cold starts with residual water, particularly in the bottom part of the edge region was performed. It revealed in 3 of 9 investigated cold starts that in a small area in the flowfield, adjacent to the water clusters in the edge channel, the water production rate was reduced during the cold start from the point where the cell voltage showed a bend and the HFR began to rise up. The relevant area never exceeded $3 \mathrm{~cm}^{2}$. In the case shown in Figure 6 , the produced water amount was reduced by almost $50 \%$ in the area close to the residual water cluster in the edge 
channel (region I) compared to the average over the whole cell. In the rest of the cell no significant deviation from the mean water production was found.

One theory for the reduced water production rate in region $\mathrm{I}$ is, that residual water is already frozen there when starting the cell from sub-zero temperatures, posing a nucleus for further freezing of generated product water. But as the initial water thickness in region I lies in the same range as in the other areas, the rest of the cell would be expected to show the same behavior. A possible explanation for that inconsistency is that in the rest of the cell, water is located in the membrane as non-freezable water or in the CL where the freezing point is depressed, while in region $\mathrm{I}$ it is located in the GDL or flowfield, caused by diffusive transport from the adjacent water cluster in the edge channel. Another possible explanation is that the frozen residual water cluster in the edge channel poses a nucleus for freezing of the generated product water in a limited area around it. In the meantime the rest of the product water around that area remains in a non-frozen or supercooled state. This implies, that water clusters in a cell exist separated from each other, as shown for example by Eller et al. [7], so that once freezing is initiated locally in the cell, it cannot spread out over the whole cell area. The theory of isolated water clusters was also discussed elsewhere [15,27].

Our results reveal that residual water in a cell has a generally negative influence on cold start capability. This can be a crucial issue. Apart from the described mechanisms, residual water in the edge region of a cell can also be redistributed over the whole cell area by diffusion in the membrane or porous layers during system downtime. Cell design and in particular sealing concepts should therefore aim to minimize void areas in the cell which could favor local water accumulations outside the flowfield area.

\subsection{Preferential Water Pathways in Porous Layers}

In all cold starts from $-5{ }^{\circ} \mathrm{C}$ and below not a single droplet was seen to be drained into the flowfield in the neutron radiograms. All water seems to be retained in one of the porous layers. However, as soon as the cell was heated up after a failed cold start, droplets emerged into the flowfield over the whole cell plane at about $2.5^{\circ} \mathrm{C}$. Figure 7 shows the water distribution in the cell during heat up after three different (!) cold starts from $-5{ }^{\circ} \mathrm{C}$. The accumulated charge current density over the 
whole cold starts $\mathrm{q}_{\mathrm{CS}}$ laid in the range from 30 to $33 \mathrm{C} \mathrm{cm}^{-2}$ for all three cases. Note that the cell was dried and re-conditioned before each start according to the standard protocol.

During a cold start water is frozen in the place of its main percolation pathways in the CL and GDL. Imaging cold starts with neutron radiography provides a further insight into water transport processes in porous layers. When a cell is thawed after a failed cold start, water drains out right at its recent position in the pores and gives an indication of the main transport pathways. The results show an astonishing coinciding image of water droplet distribution and even droplet shape after subsequent cold starts of the same cell with consistent operation conditions. It proves that preferential water percolation paths in the porous layers of a PEFC exist, as already found out by the means of other methods [28,29]. The results also prove that isothermal cold starts in combination with neutron radiography could be a promising noninvasive method to investigate water transport in the porous layers of PEFCs in detail.

\section{Conclusions}

In this work isothermal cold starts of a $50 \mathrm{~cm}^{2} \mathrm{PEFC}$ at startup temperatures from -2.5 to $-10{ }^{\circ} \mathrm{C}$ were performed. Beside the measurement of electrochemical parameters, in-plane water distribution was imaged by the means of neutron radiography. In contrast to other works, we separated the total charge drawn during the cold start in phases (membrane water uptake, stable operation, cell failure). A further particularity of this work is that we took into account realistic sealing solutions and assessed the effect of residual water not only in the flowfield but also in the edge region of the cell. The key findings are the following:

1. The initial membrane humidification (measured by the cell high frequency resistance) shows a clear correlation with the charge drawn during the first phase of a cold start (membrane water uptake) but no visible correlation with the rest of the startup duration.

2. Freezing of residual water clusters in a cell during cool down below $0{ }^{\circ} \mathrm{C}$ was directly verified by dual spectrum neutron imaging.

3. Residual water (e.g. in porous media or flowfields) was proved to have a slight negative influence on cold start capability. However, the conditioning procedure did not allow to distinguish between the influence of the residual water in the edge region and the flowfield. 
4. Residual water in the edge channel of a cell caused an adjacent fraction of the flowfield with an area of up to $3 \mathrm{~cm}^{2}$ to produce less water compared to the rest of the cell. It was shown that residual water in the edge channel freezes before starting the cell from sub-zero temperatures and causes the generated product water in the surrounding cell area to freeze early during a cold start. This emphasizes the importance of the cell design in its outer perimeter regarding cold start capability.

5. Water pathways through CL and GDL during a cold start were identified to be consistent between different cold starts, supporting the theory of preferential water transport pathways in the porous layers.

\section{Acknowledgments}

This work was carried out with the support of the European Community. We appreciate the support of the European Research Infrastructure H2FC European Infrastructure (funded under the FP7 specific program Capacities, Grant Agreement Number 284522) and its partner the Paul Scherrer Institute. 


\section{Tables}

Table 1: Standard experimental protocol for cold starts, adapted from [15].

\begin{tabular}{|c|c|c|c|}
\hline No. & Step name & Operating conditions & $\begin{array}{l}\text { Duration/Condition } \\
\text { for next step }\end{array}$ \\
\hline 1 & Drying & $\begin{array}{l}\mathrm{T}_{\text {cell }}=25^{\circ} \mathrm{C}, \mathrm{V}_{\mathrm{ca}}=1.5 \mathrm{l} / \mathrm{min} \mathrm{V}_{\text {an }}=0.6 \\
1 / \mathrm{min}, \text { dry } \mathrm{N}_{2}\end{array}$ & $\mathrm{HFR} \geq 0.5 \Omega \mathrm{cm}^{2}$ \\
\hline 2 & $\begin{array}{l}\text { Water } \\
\text { production }\end{array}$ & $\begin{array}{l}\text { current density } 0.2 \mathrm{~A} \mathrm{~cm}^{-2} \\
\lambda_{\mathrm{an} / \mathrm{ca}}=4\end{array}$ & $\begin{array}{l}\text { variable (1 to } 10 \\
\text { min) }\end{array}$ \\
\hline 3 & Pipe blow & $\mathrm{V}_{\mathrm{an} / \mathrm{ca}}=0.21 / \mathrm{min}$, dry $\mathrm{N}_{2}$ & $15 \mathrm{~s}$ \\
\hline 4 & Subcooling & $\mathrm{T}_{\text {cell }}=-15^{\circ} \mathrm{C}$ & $\mathrm{T} \pm 0.5^{\circ} \mathrm{C}$ \\
\hline 5 & Heating & To desired start temperature & $\mathrm{T} \pm 0.5^{\circ} \mathrm{C}$ \\
\hline 6 & Gas flows & $\lambda_{\mathrm{an} / \mathrm{ca}}=8.5$ (ref. to current of step 7) & $\mathrm{U}_{\text {cell }}>0.8 \mathrm{~V}$ \\
\hline 7 & Operation & $\begin{array}{l}\text { current ramp } 0.01 \mathrm{~A} \mathrm{~cm}^{-2} \mathrm{~s}^{-1} \\
\text { current density between } 0.02 \text { and } 0.2 \mathrm{~A} \\
\mathrm{~cm}^{-2} \\
\lambda_{\mathrm{an} / \mathrm{ca}}=8.5\end{array}$ & $\mathrm{U}_{\text {cell }}<0.2 \mathrm{~V}$ \\
\hline 8 & Imaging & No gas flows & $10 \mathrm{~min}$ \\
\hline 9 & Heating-up & $\mathrm{T}_{\text {cell }}=25^{\circ} \mathrm{C}$ & $\mathrm{T} \pm 0.5^{\circ} \mathrm{C}$ \\
\hline
\end{tabular}

\section{Figures}

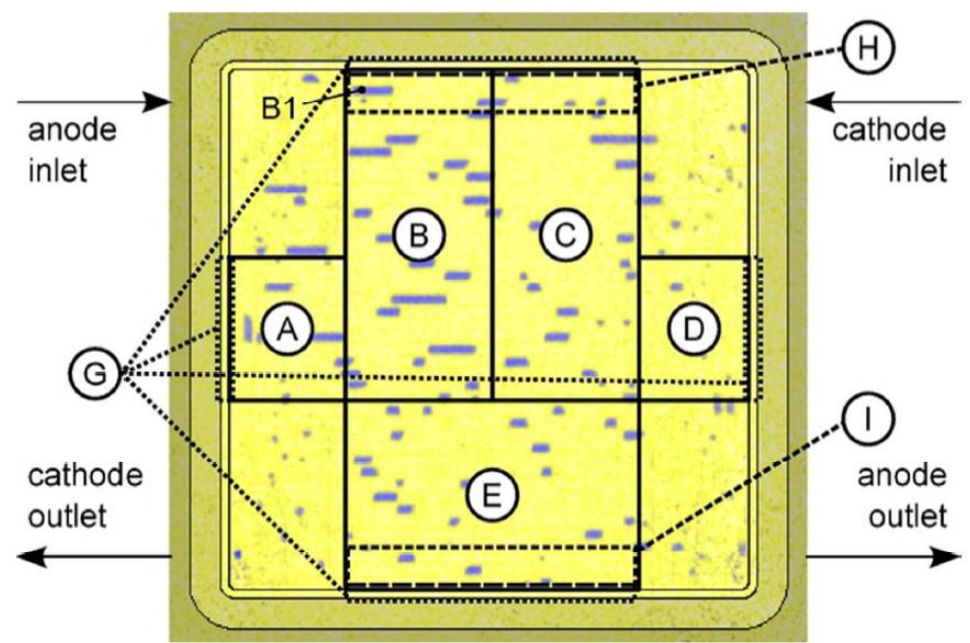

Figure 1: Averaging areas of the cell for analysis of the local water thickness. The image shows an exemplary cold start from $-2.5{ }^{\circ} \mathrm{C}$ at a current density of $0.04 \mathrm{~A} \mathrm{~cm}^{-2}$. Water accumulations are indicated in blue. 


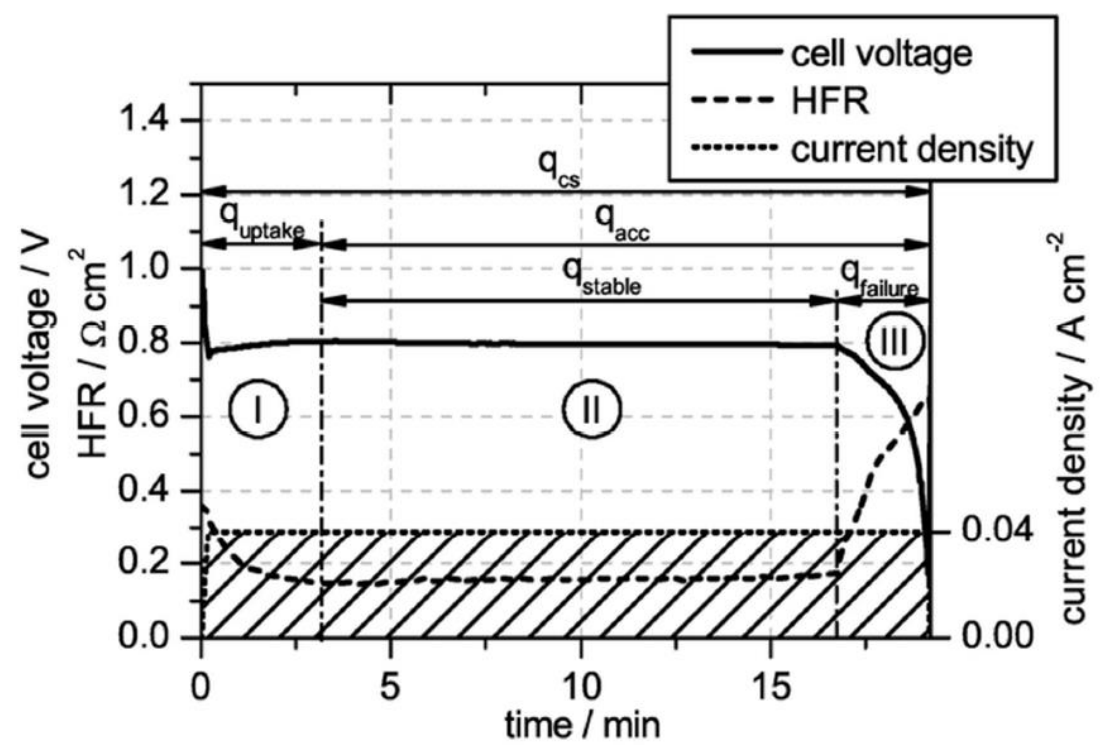

Figure 2: Exemplary isothermal cold start at $-5{ }^{\circ} \mathrm{C}$ and $0.04 \mathrm{~A} \mathrm{~cm}^{-2}$, with the different phases indicated. Phase I: water uptake of the membrane, Phase II: stable cell operation, Phase III: cell breakdown. Also the accumulated charge current densities q assigned to the different phases are shown.

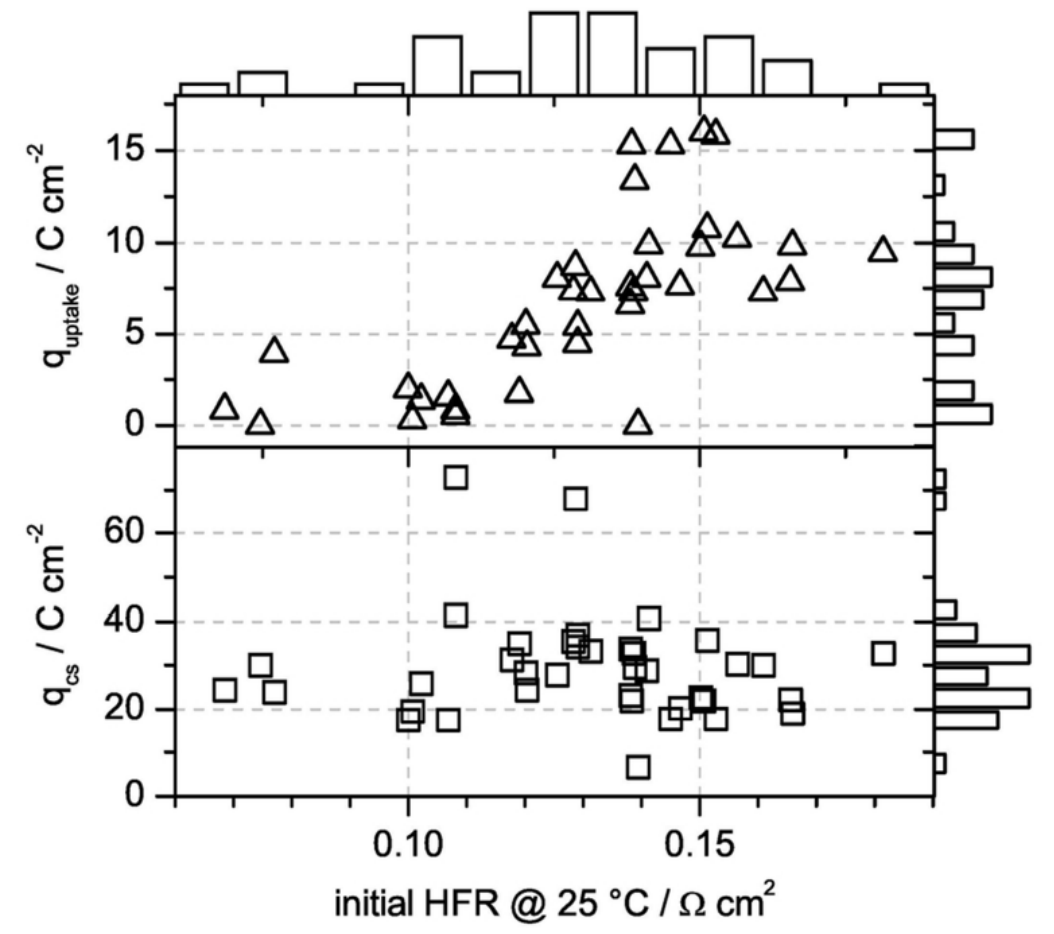

Figure 3: Dependency of $\mathrm{q}_{\mathrm{CS}}$ and $\mathrm{q}_{\text {uptake }}$ from the initial HFR before cooling down the cell. Each data point represents a single cold start, performed at $-5{ }^{\circ} \mathrm{C}$ and at current densities between 0.02 and $0.2 \mathrm{~A} \mathrm{~cm}^{-2}$. 


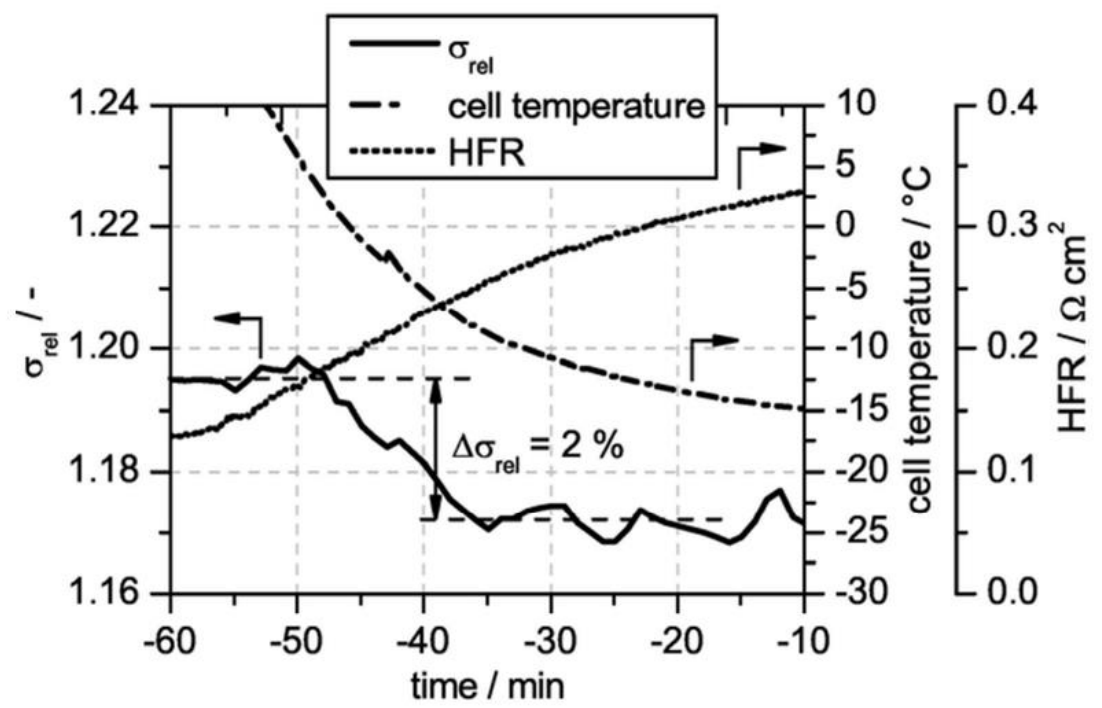

Figure 4: $\sigma_{\text {rel }}$ of a residual water cluster in the edge channel (bottom part of region $G$ in Figure 2) during cool down as a measure for phase transitions. A negative step of $\sigma_{\text {rel }}$ by $2 \%$ clearly proves a phase transition from water to ice. Time on the x-axis refers to the beginning of the following cold start.

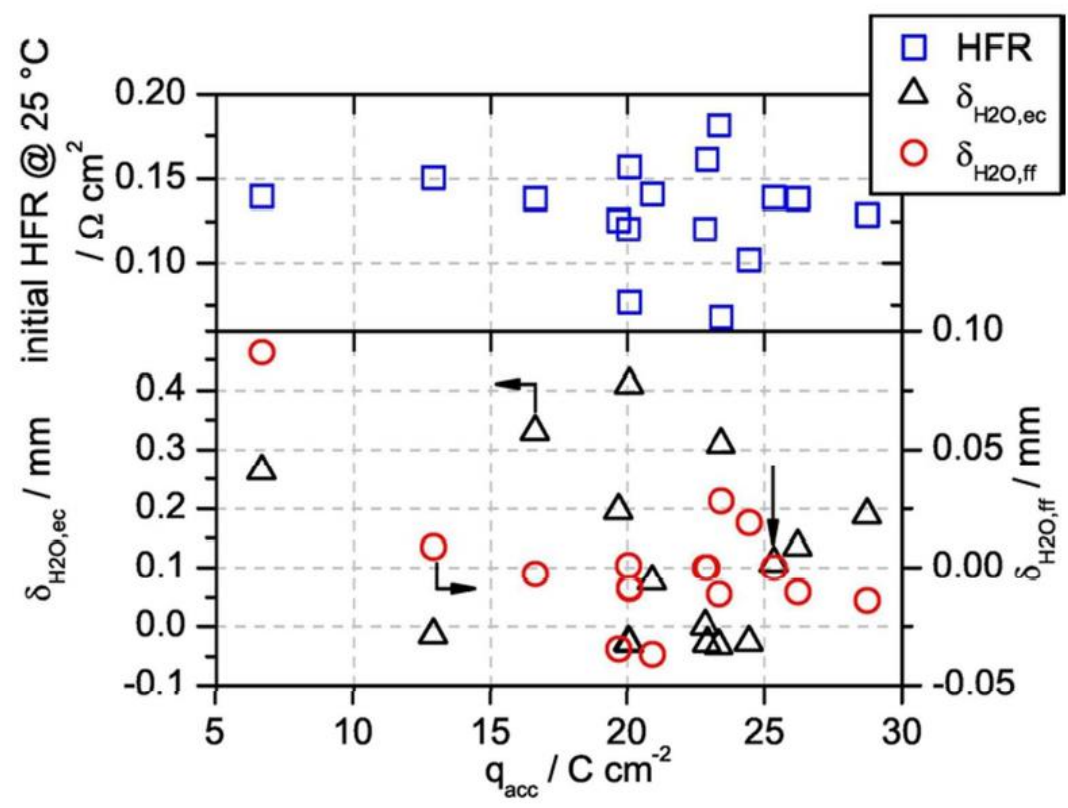

Figure 5: Initial HFR at $25{ }^{\circ} \mathrm{C}$ before a cold start and water thickness in the flowfield $\delta_{\mathrm{H} 2 \mathrm{O}, \mathrm{FF}}$ and in the edge channel $\delta_{\mathrm{H} 2 \mathrm{O}, \mathrm{EC}}$ for different cold starts over the accumulated charge current density of phase II and III qacc. All cold starts were performed at $-5{ }^{\circ} \mathrm{C}$ and $0.04 \mathrm{~A} \mathrm{~cm}^{-2}$. The vertical arrow indicates the investigated cold start in Figure 6. 


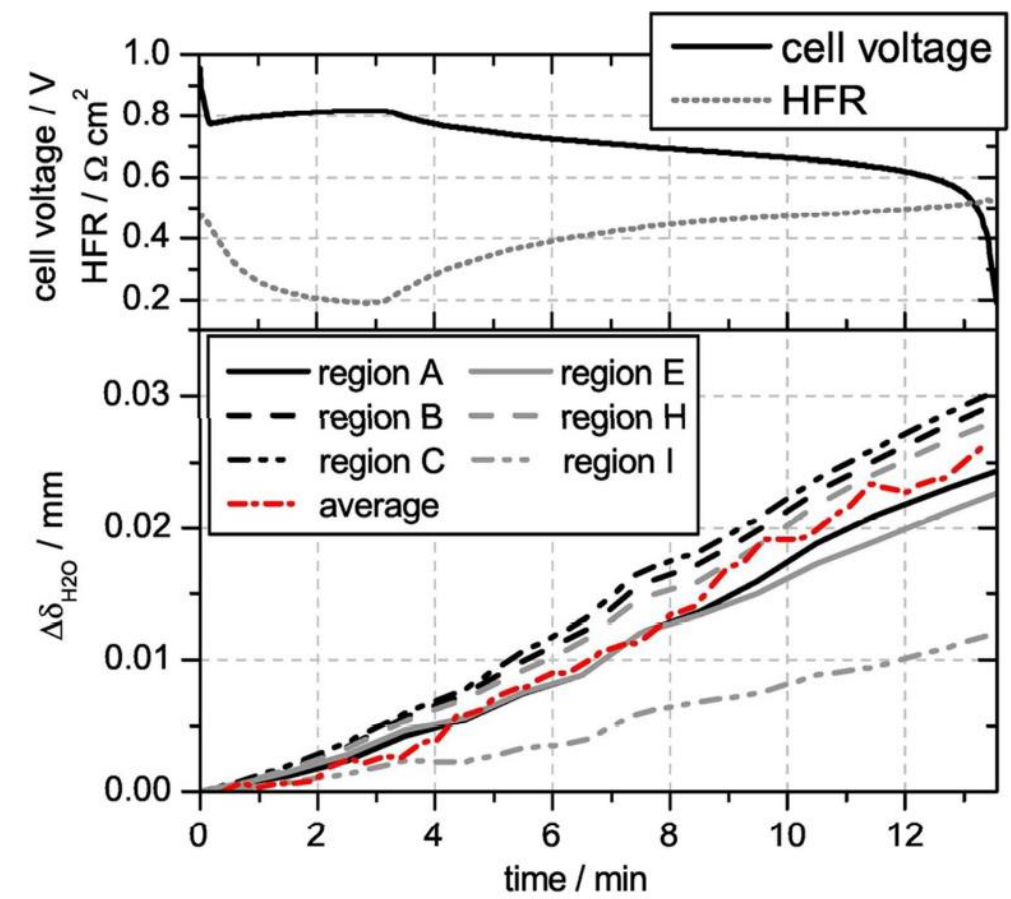

Figure 6: Electrochemical data and evolution of water thicknesses in a cell for a cold start from $5{ }^{\circ} \mathrm{C}$ with residual water in the bottom part of the edge channel.
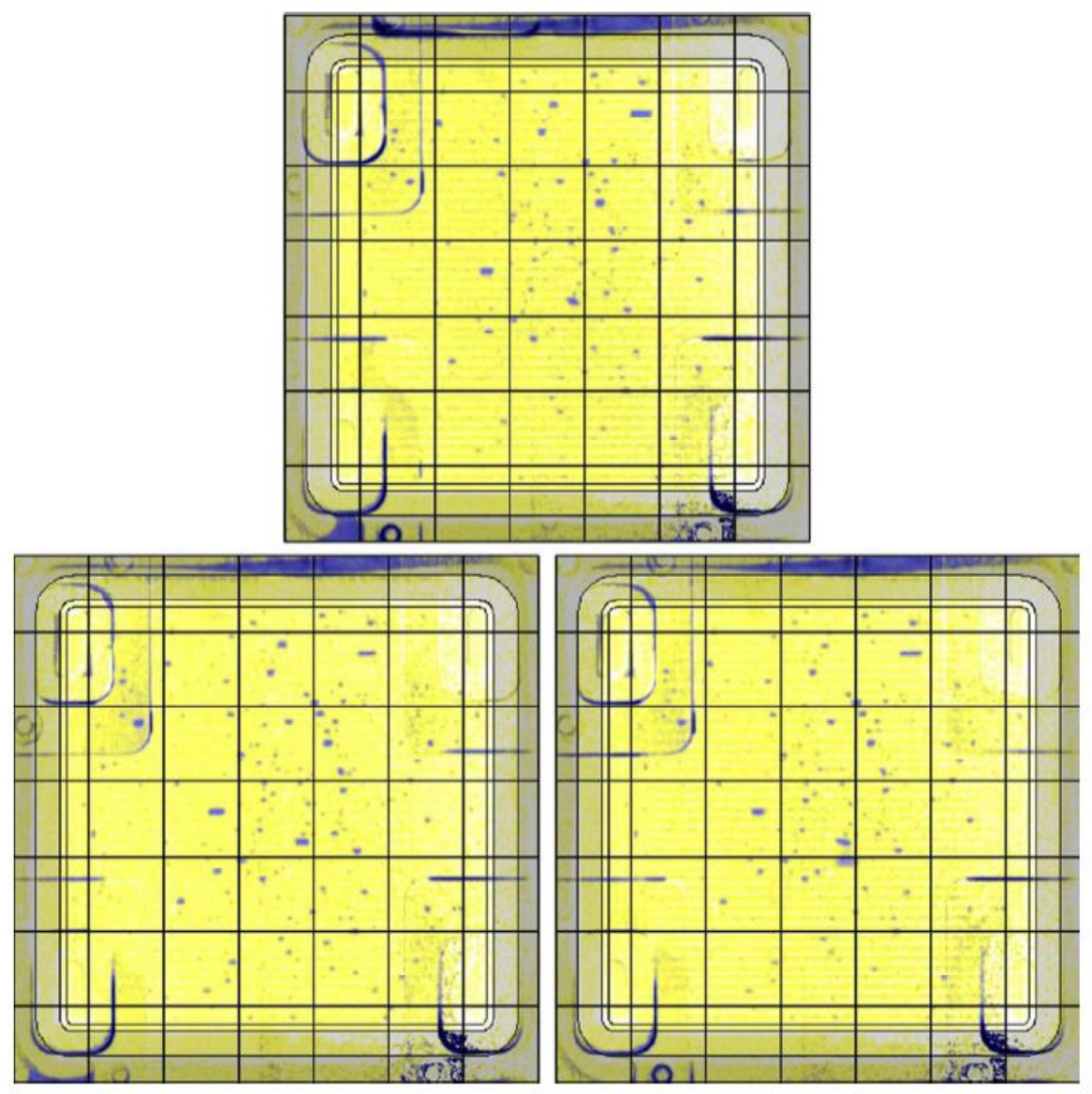

Figure 7: Water distribution in the cell during heating up at $5{ }^{\circ} \mathrm{C}$, after three different cold starts. Grids are drawn to facilitate comparison of the images. 


\section{References}

[1] P. Stahl, J. Biesdorf, P. Boillat, J. Kraft, K.A. Friedrich, J. Electrochem. Soc. 2015, 162, F677

[2] Y. Ishikawa, T. Morita, K. Nakata, K. Yoshida, M. Shiozawa, J. Power Sources 2007, 163, 708

[3] Y. Ishikawa, H. Hamada, M. Uehara, M. Shiozawa, J. Power Sources 2008, 179, 547

[4] Y. Ishikawa, M. Shiozawa, M. Kondo, K. Ito, Int. J. Heat Mass Tran. 2014, 74, 215

[5] J. Biesdorf, P. Oberholzer, F. Bernauer, A. Kaestner, P. Vontobel, E. H. Lehmann, T. J. Schmidt, P. Boillat, Physical Review Letters 2014, 112, 248301

[6] T. J. Dursch, M. A. Ciontea, C. J. Radke, A. Z. Weber, Langmuir 2012, 28, 1222

[7] J. Eller, X-Ray Tomographic Microscopy of Polymer Electrolyte Fuel Cells, Phd Thesis No. 20916, ETH Zürich, 2013

[8] A. Siu, J. Schmeisser, S. Holdcroft, J. Phys. Chem. B 2006, 110, 6072

[9] E. L. Thompson, T. W. Capehart, T. J. Fuller, J. Jorne, J. Electrochem. Soc. 2006, 153, A2351

[10] H. Mendil-Jakani, R. J. Davies, E. Dubard, A. Guillermo, G. Gebel, J. Membrane Sci. 2011, 369,148

[11] E. Pinton, Y. Fourneron, S. Rosini, L. Antoni, J. Power Sources 2009, 186, 80

[12] E. L. Thompson, J. Jorne, W. Gu, H. A. Gasteiger, J. Electrochem. Soc. 2008, 155, B887

[13] E. L. Thompson, J. Jorne, W. Gu, H. A. Gasteiger, J. Electrochem. Soc. 2008, 155, B625

[14] C. Chacko, R. Ramasamy, S. Kim, M. Khandelwal, M. Mench, J. Electrochem. Soc. 2008, $155, \mathrm{~B} 1145$

[15] P. Stahl, J. Biesdorf, P. Boillat, K. A. Friedrich, J. Electrochem. Soc., 2016, 163, F1535

[16] A. P. Kaestner, S. Hartmann, G. Kühne, G. Frei, C. Grünzweig, L. Josic, F. Schmid, E. H. Lehmann, The ICON beamline - A facility for cold neutron imaging at SINQ, Nuclear Instruments and Methods in Physics Research A 2011, 659, 387

[17] W. J. Moore, Physikalische Chemie, 4th ed., D. O. Hummel, Editor, p. 889, de Gruyter, Berlin, 1986

[18] L. Josic, E. H. Lehmann, D. Mannes, N. Kardjilov, A. Hilger, Nucl. Instrum. Meth. A 2012, 670,68

[19] L. Torres, J. R. Granada, J. J. Blostein, Nucl. Instrum. Meth. B 2006, 251, 304 
[20] J. Biesdorf, Neutron radiography of Polymer Electrolyte Fuel Cells: From conventional towards energy selective neutron imaging, Phd Thesis No. 23308, ETH Zürich, 2016

[21] P. Boillat, J. Biesdorf, P. Oberholzer, Accuracy of water quantification in fuel cells by neutron imaging, Paul Scherrer Institute, Annual Report, 2013

[22] A. Morin, Z. Peng, J. Jestin, M. Detrez, G. Gebel, Solid State Ionics 2013, 252, 56

[23] M. Oszcipok, D. Riemann, U. Kronenwett, M. Kreideweis, M. Zedda, J. Power Sources 2005, 145,407

[24] P. Oberholzer, P. Boillat, R. Siegrist, R. Perego, A. Kästner, E. Lehmann, G. G. Scherer and A. Wokaun, Journal of The Electrochemical Society, 2011, 159, B235

[25] K. Tajiri, Y. Tabuchi, C.-Y. Wang, J. Electrochem. Soc. 2007, 154, B147

[26] T. J. Dursch, M. A. Ciontea, G. J. Trigub, C. J. Radke, A. Z. Weber, Int. J. Heat Mass Tran. $2013,60,450$

[27] J. Biesdorf, P. Stahl, M. Siegwart, T. J. Schmidt, P. Boillat, J. Electrochem. Soc. 2015, 162, F1231

[28] A. M. J. Bazylak, Liquid water transport in fuel cell gas diffusion layers, Phd Thesis, University of Victoria, 2008

[29] S. Litster, D. Sinton, N. Djilali, J. Power Sources 2006, 154, 95 